\title{
A rapid, convenient, solventless green approach for the synthesis of oximes using grindstone chemistry
}

\author{
Lakhinath Saikia', Jejiron Maheswari Baruah² and Ashim Jyoti Thakur ${ }^{1 *}$
}

\begin{abstract}
Background: Synthesis of oximes is an important reaction in organic chemistry, because these versatile oximes are used for protection, purification, and characterization of carbonyl compounds. Nitriles, amides via Beckmann rearrangement, nitro compounds, nitrones, amines, and azaheterocycles can be synthesised from oximes. They also find applications for selective $\alpha$-activation. In inorganic chemistry, oximes act as a versatile ligand.

Several procedures for the preparation of oximes exist, but, most of them have not addressed the green chemistry issue. They are associated with generation of pollutants, requirement of high reaction temperature, low yields, lack of a generalized procedure, etc. Hence, there is a demand for developing an efficient, convenient, and non-polluting or less polluting alternative method for the preparation of oximes. In this context, bismuth compounds are very useful as they are cheap in general, commercially available, air stable crystalline solids, safe, and non-toxic, hence easy to handle.
\end{abstract}

Results: Carbonyl compounds (aliphatic, heterocyclic, and aromatic) were converted into the corresponding oximes in excellent yields by simply grinding the reactants at room temperature without using any solvent in the presence of $\mathrm{Bi}_{2} \mathrm{O}_{3}$. Most importantly, this method minimizes waste disposal problems, provides a simple yet efficient example of unconventional methodology and requires short time.

Conclusions: We have developed a novel, quick, environmentally safe, and clean synthesis of aldoximes and ketoximes under solvent-free grinding condition.

Keywords: oximes, carbonyl compounds, $\mathrm{Bi}_{2} \mathrm{O}_{3}$, grindstone chemistry, solventless, eco-friendly

\section{Background}

Conversion of carbonyl functionalities into oximes is an important reaction in organic chemistry. Oximes are highly crystalline compounds that find applications not only for protection, but also for purification and characterization of carbonyl compounds [1,2].Conversions into nitriles [3], nitro compounds [4,5], nitrones [6], amines [7], and synthesis of azaheterocycles [8] are some of the synthetic applications of oximes. They are also useful for selective $\alpha$-activation [9] and are extensively used as intermediates for the preparation of amides by the Beckmann rearrangement $[10,11]$ and fungicides and herbicides [12]. In inorganic chemistry, oximes act as a versatile ligand.

Classically, oximes are prepared [2] by refluxing an alcoholic solution of a carbonyl compound with

\footnotetext{
* Correspondence: ashim@tezu.ernet.in

'Department of Chemical Sciences, Central University, Tezpur, Napaam,

Tezpur 784028, Assam, India

Full list of author information is available at the end of the article
}

hydroxylamine hydrochloride and pyridine. The method has multiple drawbacks such as low yields, long reaction time, toxicity of pyridine, and effluent pollution caused by the use of organic solvent. In recent times, solventfree reactions have drawn considerable attention and popularity $[13,14]$, not only from an environmental point of view, but also for synthetic advantages in terms of yield, selectivity, and simplicity of the reaction procedure. Since chemical industry deals with larger quantity of materials, these factors are particularly very important therein. Over the years, many reagents and catalysts have been developed for the synthesis of oximes. Basic aluminia [15], $\mathrm{CaO}[16]$, and $\mathrm{TiO}_{2} /\left(\mathrm{SO}_{4}{ }^{2-}\right)$ [17] coupled with microwave irradiation under solvent-free condition have been claimed to be efficient methods for the preparation of oximes. Hashem Sharghi and Hosseini [18] described a solventless reaction protocol for synthesizing aldoximes from corresponding aldehydes using $\mathrm{ZnO}$ as catalyst at $80^{\circ} \mathrm{C}$. Interestingly, they obtained Beckmann rearrangement product at higher temperatures $\left(140-170^{\circ}\right.$

\section{Springer}


C). More recently, conversion of carbonyl compounds to oximes in aqueous biphasic medium and ionic liquid/ water biphasic system $[19,20]$ has been reported. However, problems of generation of polluting $\mathrm{HCl}$, high reaction temperature, occasionally low yields, and lack of a generalized procedure covering all types of aldehydes and ketones still present. Consequently, there is a demand for developing an efficient, convenient, and non-polluting or less polluting alternative method for the preparation of oximes. In this context, because of the rich chemistry of bismuth compounds [21-25], we became interested therein. Bismuth compounds are generally cheap, commercially available, air stable crystalline solids, safe, and non-toxic, hence easy to handle. Their Lewis acidity is also well known [26,27]. Most bismuth (III) compounds have an $\mathrm{LD}_{50}$ value which is comparable to or even less than that of $\mathrm{NaCl}$ [28].

In continuation to our interest in protection and deprotection chemistry $[29,30]$, we have developed a novel, quick, environmentally safe, and clean synthesis of aldoximes and ketoximes under grinding condition (Scheme 1) utilizing pestle and mortar under solventfree condition. The method makes use of local heat generated by simply grinding the reactants and catalyzed by cheap and commercially available $\mathrm{Bi}_{2} \mathrm{O}_{3}$ for driving the chemical reaction at room temperature. The work up is easy and furnished the oximes in excellent yields. Most importantly, this method minimizes waste disposal problems and provides a simple yet efficient example of unconventional methodology, which is equally effective for all types of aldehydes and ketones. Earlier reports $[15,31]$ of similar type restricted their utility in carbonyl compounds (alicyclic and aliphatic) and aromatic aldehydes only and aromatic ketoximes were not obtained. In those reports, for ketoxime synthesis, microwave irradiation or addition of some other additives was necessary. In this regard, our method is superior, quite general, and versatile.

\section{Results and discussion}

In the present solvent-free method, the effectiveness of $\mathrm{Bi}_{2} \mathrm{O}_{3}$ in oxime synthesis (see Scheme 1) under grinding

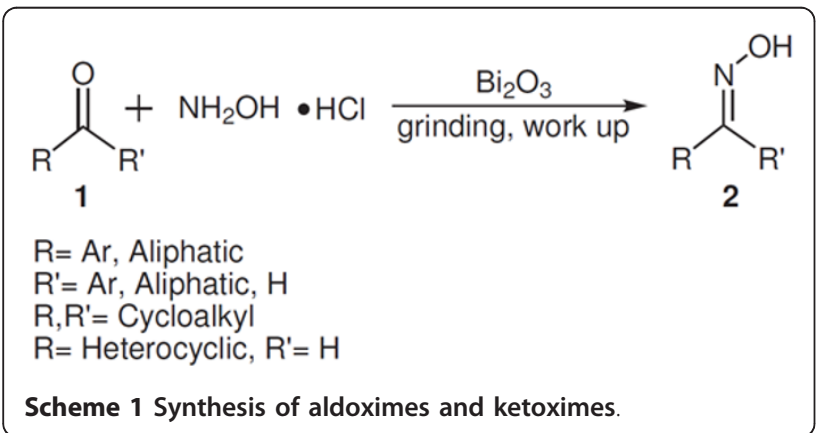

condition is demonstrated using a broad spectrum of aldehydes and ketones with hydroxylamine hydrochloride in the absence of a base or any other additives. To search for the best reaction condition for oximation using easily available bismuth compounds, a set of reactions have been carried out using $p$-chlorobenzaldehyde and hydroxylamine hydrochloride as substrates under various reaction conditions at constant catalyst $\left(\mathrm{Bi}_{2} \mathrm{O}_{3}\right.$ and $\mathrm{BiOCl}$ ) loading (50 $\mathrm{mol} \%$ with respect to substrate). Figure 1 summarizes the results, which clearly shows that the $\mathrm{Bi}_{2} \mathrm{O}_{3}$ under solvent-free grinding condition is the most effective.

After surveying a series of reaction conditions, the optimized results are summarized in Table 1. Aromatic, aliphatic, heterocyclic, and $\alpha, \beta$-unsaturated aldehydes were converted to the corresponding oximes in almost quantitative yields within very short time (1.5-3 min, entries 1a-k, Table 1). Cinnamaldehyde (entry $1 \mathrm{j}$, Table 1 ) was smoothly converted to cinnamaldehyde oxime without any rearrangement of $\alpha, \beta$-double bond. For ketones (acyclic and cyclic), however, reactions were comparatively difficult and took a little longer time (5.5$20 \mathrm{~min}$, entries $1 \mathrm{l}-\mathrm{q}$, Table 1). It was interesting to note that the less reactive benzophenone also condensed with hydroxylamine hydrochloride in $60 \%$ yield only that too requiring longer time, i.e., $20 \mathrm{~min}$ (entry 1q, Table 1). $5 \alpha$-Pregn-16-en- $3 \alpha$-ol-20-one acetate oxime (entry 1l, Table 1) was obtained in $88 \%$ yield within $6 \mathrm{~min}$. The unreacted materials were recovered from the reaction mixture. No observable difference in reactivity exerted by $-\mathrm{NO}_{2}$ group at $m$ - or $p$-position was noticed (entries $1 \mathrm{~b}$ and $\mathrm{c}$, Table 1), being yields and reaction times were almost same. Entities such as chloro, nitro, hydroxyl were found to be inert to the reaction condition. The products were identified by their spectral $\left({ }^{1} \mathrm{H} N M R,{ }^{13} \mathrm{C}\right.$ NMR, IR spectra) data, physical data (melting point, elemental analysis), and comparison with authentic ones. IR spectra supported this observation as no peak was observed around $2200 \mathrm{~cm}^{-1}$ characteristic of the $-\mathrm{C} \equiv \mathrm{N}$ group. However, appearance of peaks around 3200-3450 and $1600-1680 \mathrm{~cm}^{-1}$ are indicative of $-\mathrm{OH}$ and $>\mathrm{C}=\mathrm{N}$ groups, respectively. $\mathrm{In}^{1} \mathrm{H}$ NMR spectra, the $-\mathrm{OH}$ signal of oximes appeared within $\delta=8.0-10.00 \mathrm{ppm}$ as a broad singlet (characteristic signal) that was exchangeable with $\mathrm{D}_{2} \mathrm{O}$. It was very appealing that in these reactions neither the dehydration product, nitriles, nor the amides, via Beckmann rearrangement were observed. The reaction was very clean and no other product was observed.

To evaluate the synergy between rate, yield, and $\mathrm{Bi}_{2} \mathrm{O}_{3}$ loading in this reaction, several experiments were carried out. In a pilot experiment, the reaction was found to proceed poorly in the absence of $\mathrm{Bi}_{2} \mathrm{O}_{3}$. As far as $\mathrm{Bi}_{2} \mathrm{O}_{3}$ loading is concerned, $60 \mathrm{~mol} \%$ of the 


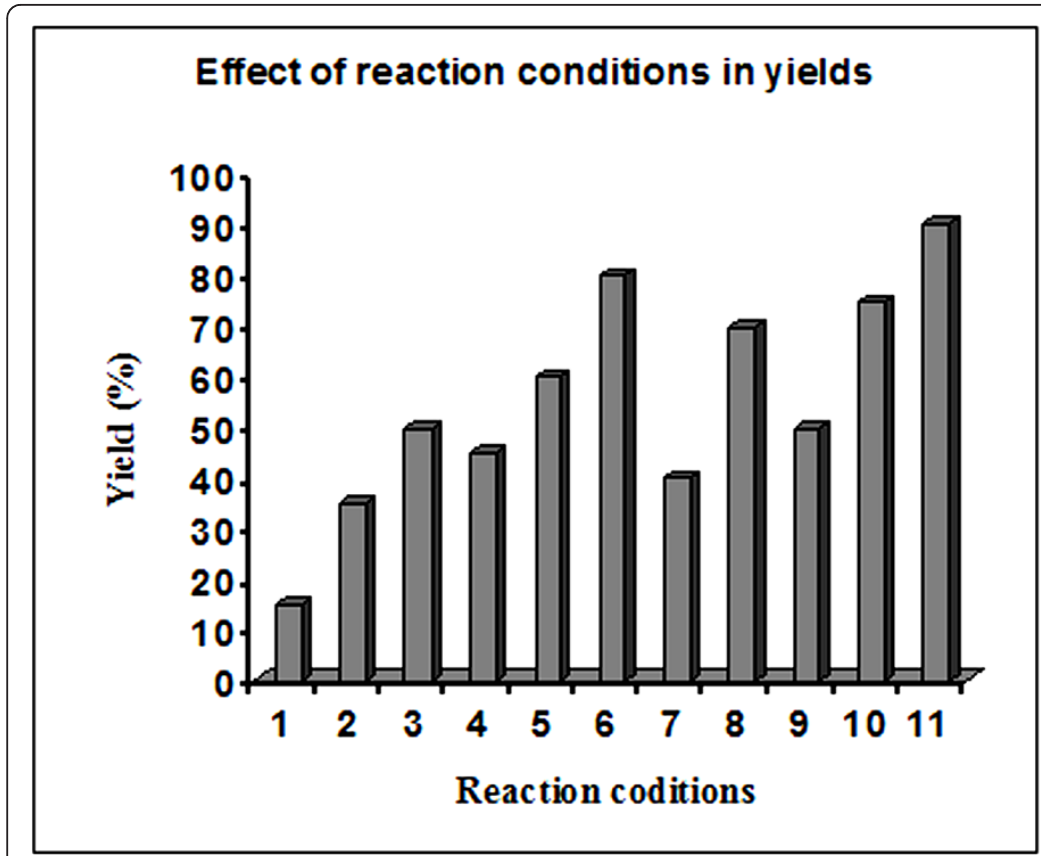

1. Without catalyst, grinding, $2 \mathrm{hrs}$

2. $\mathrm{BiOCl}, \mathrm{H}_{2} \mathrm{O}$, r.t., $12 \mathrm{hrs}$

3. $\mathrm{BiOCl}, \mathrm{H}_{2} \mathrm{O}$, reflux, $3 \mathrm{hrs}$

4. $\mathrm{BiOCl}, \mathrm{EtOH}$, r.t., $12 \mathrm{hrs}$

5. $\mathrm{BiOCl}, \mathrm{E}$ tOH, reflux, $3 \mathrm{hrs}$

6. $\mathrm{BiOCl}$, grinding, $\mathbf{4 0} \mathrm{mins}$

7. $\mathrm{Bi}_{2} \mathrm{O}_{3}, \mathrm{H}_{2} \mathrm{O}$, r.t., $12 \mathrm{hrs}$

8. $\mathrm{Bi}_{2} \mathrm{O}_{3}, \mathrm{H}_{2} \mathrm{O}$, reflux, $3 \mathrm{hrs}$

9. $\mathrm{Bi}_{2} \mathrm{O}_{3}, \mathrm{E}$ tOH, r.t., $12 \mathrm{hrs}$

10. $\mathrm{Bi}_{2} \mathrm{O}_{3}, \mathrm{E}$ tOH, reflux, 3hrs

11. $\mathrm{Bi}_{2} \mathrm{O}_{3}$, grinding, 15 mins

Figure 1 Effect of reaction conditions in yields.

catalyst with respect to the substrate was the optimum one (Table 2). An increase in $\mathrm{Bi}_{2} \mathrm{O}_{3}$ loading did not improve the yield as well as no change in reaction time was observed. However, a decrease in $\mathrm{Bi}_{2} \mathrm{O}_{3}$ loading appreciably decreased the rate and yield of the reaction.

We have also checked the reusability of the catalyst using the recovered $\mathrm{Bi}_{2} \mathrm{O}_{3}$ from the reaction. It is observed that recovered catalyst could be satisfactorily used for the second run, whereas, third run of the recovered catalyst leads to poor yield and longer reaction time (Table 3). The surface areas of the fresh as well as the recovered catalyst after the third run in the reaction were determined in a surface area and pore size analyzer and found to be 5.21 and $37.106 \mathrm{~m}^{2} / \mathrm{g}$, respectively. The average particle diameters of the fresh as well as the recovered catalyst after the third run in the reaction were calculated out from these measured surface areas and were found to be 129.396 and $18.168 \mathrm{~nm}$, respectively. The increase in granularity of the catalyst after reuse is obvious since it was grounded. However, the decrease in efficiency of the catalyst after the third run might be due to the loss of active sites of the catalyst.

\section{Conclusions}

To the best of our knowledge, $\mathrm{Bi}_{2} \mathrm{O}_{3}$ has never been used in the synthesis of oximes earlier. In conclusion, the reported procedure is an interesting, extremely simple, suitable, fast, efficient, and novel method for the preparation of oximes. The methodology also offers chemical, economical, and environmental advantages. On the other hand, $\mathrm{Bi}_{2} \mathrm{O}_{3}$ is remarkably easier to use, nonhazardous, inexpensive and work under mild neutral conditions [32,33].

\section{Experimental}

Melting points were determined on a Büchi 504 apparatus and were uncorrected. IR spectra were recorded in $\mathrm{KBr}$ pallets on a Nicolet (Impact 410) FT-IR spectrophotometer. ${ }^{1} \mathrm{H}$ NMR and ${ }^{13} \mathrm{C}$ NMR spectra were recorded on a JNM ECS $400 \mathrm{MHz}$ FT-NMR (JEOL) spectrophotometer with TMS as the internal standard. Mass spectra were recorded on a Waters Q-TOF Premier \& Aquity UPLC spectrometer. Surface area of the catalyst before and after use in the reaction was measured using surface area \& pore size analyzer (NOVA 1000e, Quanta chrome Instruments). All the chemicals were used as-received.

\section{Methods}

5.1. Typical procedure for the formation of oxime 2

A mixture of aldehyde/ketone 1 (1 mmol), hydroxylamine hydrochloride $(1.2 \mathrm{mmol})$, and $\mathrm{Bi}_{2} \mathrm{O}_{3}(0.6 \mathrm{mmol})$ was grounded in a mortar with a pestle for the required period of time. On completion of the reaction as monitored by TLC, ethyl acetate $(2 \times 10 \mathrm{~mL})$ was added to the reaction mixture and filtered to separate the $\mathrm{Bi}_{2} \mathrm{O}_{3}$. The filtrate was concentrated down to approx. $6 \mathrm{~mL}$, then added water to it when product precipitated out from the 


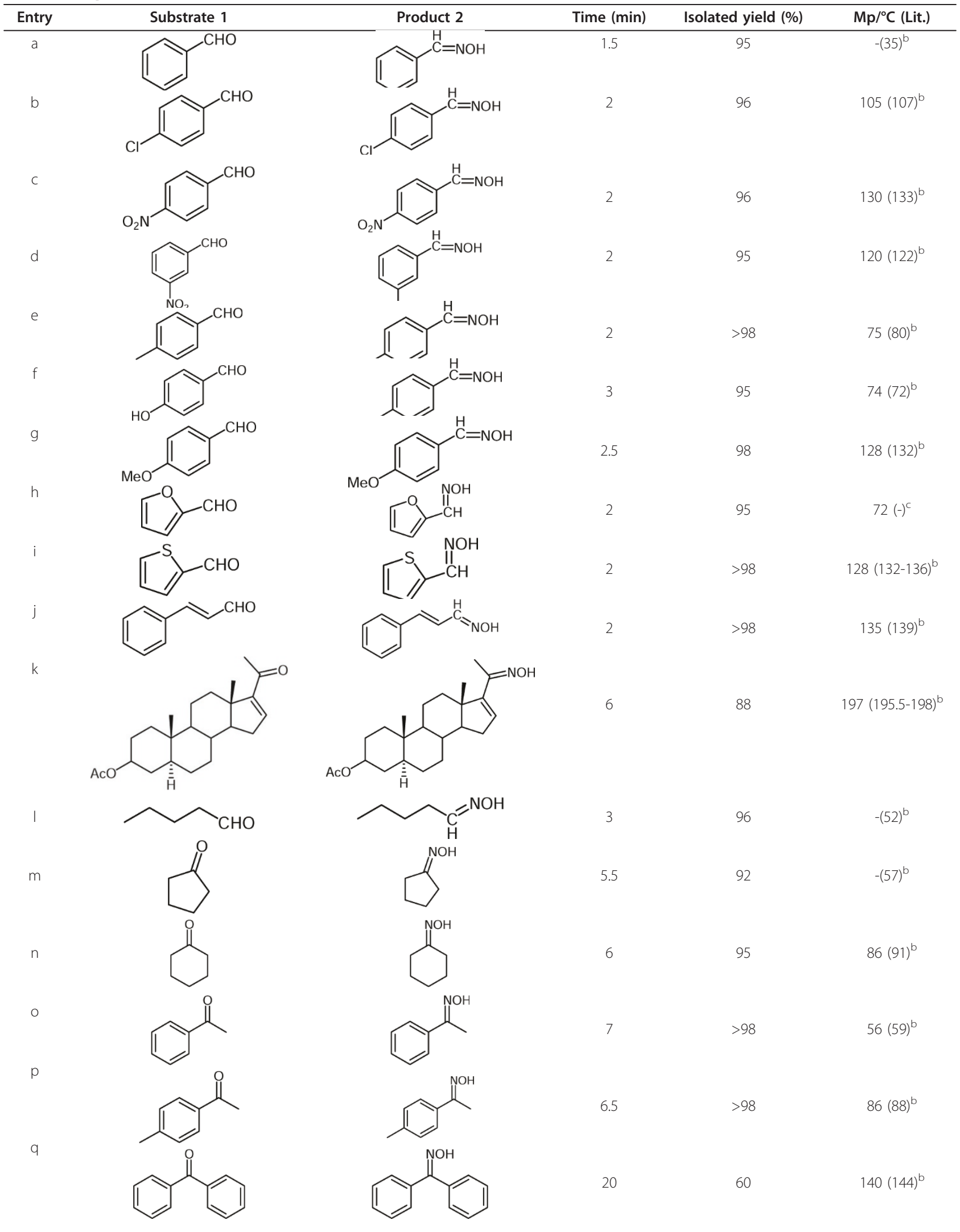

${ }^{a}$ All compounds were characterized on the basis of $I R,{ }^{1} \mathrm{H}$ and ${ }^{13} \mathrm{C}$ NMR spectral data, Mass spectrometry data and $\mathrm{m}_{\mathrm{p}}$.

b (i) Furniss BS, Hannaford AJ, Smith PWG, Tatchell AR (2008) Vogel's textbook of practical organic chemistry, 5th edn. Pearson Education, Dorling Kindersley (India). (ii) Alfa-Aesar Research Chemicals, Metals and Materials catalogue, 2008-2009.

${ }^{\mathrm{N}}$ Not found in the literature. 
Table 2 Optimization of catalyst loading in preparation of $\mathbf{2 b}$

\begin{tabular}{llll}
\hline Entry & Catalyst loading (mol\%) & Time & Yield (\%) \\
\hline 1 & No & $2 \mathrm{~h}$ & 15 \\
2 & 20 & $30 \mathrm{~min}$ & 48 \\
3 & 30 & $30 \mathrm{~min}$ & 57 \\
4 & 40 & $30 \mathrm{~min}$ & 70 \\
5 & 50 & $15 \mathrm{~min}$ & 90 \\
6 & 60 & $2 \mathrm{~min}$ & 96 \\
7 & 70 & $2 \mathrm{mins}$ & 96 \\
\hline
\end{tabular}

Table 3 Reusability of $\mathrm{Bi}_{2} \mathrm{O}_{3}$ in the preparation of $\mathbf{2 b}$ using $60 \mathrm{~mol} \%$ of the catalyst

\begin{tabular}{llll}
\hline Entry & Run number & Time & Yield (\%) \\
\hline 1 & 1 & 2 & 96 \\
2 & 2 & 8 & 87 \\
3 & 3 & 20 & 52 \\
\hline
\end{tabular}

solution. The precipitate was filtered out and dried in high vacuum to furnish the pure oxime 2 in $60-98 \%$ yield.

\section{Abbreviations}

IR: infrared; $L D_{50}$ : lethal dose that kills half (50\%) of the animals tested; NMR: nuclear magnetic resonance.

\section{Acknowledgements}

The authors are very grateful to the Council of Scientific and Industrial Research (CSIR), New Delhi, India, for financial support to the project CSIR (01(2147)/07/EMR-II).

\section{Author details}

1Department of Chemical Sciences, Central University, Tezpur, Napaam, Tezpur 784028, Assam, India ${ }^{2}$ Chembiotek, Kolkata, India, C/o TCG Lifesciences Ltd., Block BN, Sector V, Salt Lake City, Kolkata 700 091, India

\section{Competing interests}

The authors declare that they have no competing interests.

Received: 31 March 2011 Accepted: 4 October 2011 Published: 4 October 2011

\section{References}

1. Sandier SR, Karo W (1989) Organic functional group preparations, 2nd edn. Academic Press: San Diego, pp 431-476

2. Greene TW, Wuts PGM (1999) Protective groups in organic synthesis, 3rd edn. Wiley: Toronto, pp 355-358

3. Dewan SK, Singh R, Kumar A (2006) One pot synthesis of nitriles from aldehydes and hydroxylamine hydrochloride using sodium sulphate (anhyd) and sodium bicarbonate in dry media under microwave irradiation. Arkivoc ii: $41-44$

4. Dave PR, Forshar F (1996) Facile preparation of 3,7-diazabicyclo[3.3.0]octane and 3,7,10-triheterocyclic[3.3.3]propellane ring systems from 1,5diazacyclooctane-3,7-derivatives. J Org Chem 61(25):8897-8903. doi:10.1021/ jo9614755.

5. Ballistreni FP, Barbuzzi E, Tomaselli GA, Toscano RM (1996) Useful oxidation procedure of oximes to nitro compounds with Benz-Mo in acetonitrile. Synletters 11:1093-1094

6. Smith PAS, Gloyer SE (1975) Oxidation of dibenzylhydroxylamines to nitrones. Effects of structure and oxidizing agent on composition of the products. J Org Chem 40(17):2508-2512. doi:10.1021/jo00905a019.
7. Negi S, Matsukura M, Mizuno M, Miyake K, Minami N (1996) Synthesis of (2R)-1-(4-Chloro-2-pyridyl)-2-(2-pyridyl)ethylamine: a selective oxime reduction and crystallization-induced asymmetric transformation. Synthesis 8:991-996

8. Narasaka K (2003) Synthesis of azaheterocycles from oxime derivatives. Pure Appl Chem 75(1):19-28. doi:10.1351/pac200375010019.

9. Whitesell JK, Whitesell MA (1983) Alkylation of ketones and aldehydes via their nitrogen derivatives. Synthesis 7:517-536

10. Ramalingan C, Park Y-T (2007) Mercury-catalyzed rearrangement of ketoximes into amides and lactams in acetonitrile. J Org Chem 72:4536-4538. doi:10.1021/jo070297k.

11. Furuya $Y$, Ishihara $K$, Yamamoto $H$ (2005) Cyanuric chloride as a mild and active Beckmann rearrangement catalyst. J Am Chem Soc 127:11240-11241. doi:10.1021/ja053441x.

12. Song BA, Liu XH, Yang S, Hu DY, Jin LH, Zhang YT (2005) Recent advance in synthesis and biological activity of oxime derivatives. Chin J Org Chem 25(5):507-525

13. Metzger JO (1998) Solvent-free organic syntheses. Angew Chem Int Ed 37:2975-2978. doi:10.1002/(SICI)1521-3773(19981116)37:213.0.CO;2-A.

14. Tanaka K, Toda F (2000) Solvent-free organic synthesis. Chem Rev 100:1025-1074. doi:10.1021/cr940089p.

15. Kad GL, Bhandari M, Kaur J, Rathee R, Singh J (2001) Solventless preparation of oximes in the solid state and via microwave irradiation. Green Chem 3:275-277. doi:10.1039/b107356g.

16. Sharjhi H, Sarvari MH (2000) A mild and versatile method for the preparation of oximes by use of calcium oxide. J Chem Res (S) 1:24-25

17. Guo JJ, Jin TS, Zhang SL, Li TS (2001) $\mathrm{TiO}_{2} / \mathrm{SO}_{4}^{2}$ : an efficient and convenient catalyst for preparation of aromatic oximes. Green Chem 3:193-195. doi:10.1039/b102067f.

18. Sharghi H, Hosseini M (2002) Solvent-free and one-step Beckmann rearrangement of ketones and aldehydes by Zinc oxide. Synthesis 8:1057-1059

19. Sloboda-Rozner D, Neumann R (2006) Aqueous biphasic catalysis with polyoxometalates: oximation of ketones and aldehydes with aqueous ammonia and hydrogen peroxide. Green Chem 8:679-681. doi:10.1039/ b604837d.

20. Luo HM, Li YQ, Zheng WJ (2005) A novel ionic liquid/water biphasic system for the preparation of oximes. Chin Chem Lett 16(7):906-908

21. Suzuki H, Ikegami T, Matano Y (1997) Bismuth in organic transformations. Synthesis 3:249-267

22. Leonard NM, Wieland LC, Mohan RS (2002) Applications of bismuth(III) compounds in organic synthesis. Tetrahedron 58:8373-8397. doi:10.1016/ S0040-4020(02)01000-1.

23. Gaspard-lloughmane H, Le Roux C (2004) Bismuth(III) triflate in organic synthesis. Eur J Org Chem 12:2517-2532

24. Aggen DH, Arnold JN, Hayes PD, Smoter NJ, Mohan RS (2004) Bismuth compounds in organic synthesis. Bismuth nitrate catalyzed chemoselective synthesis of acylals from aromatic aldehydes. Tetrahedron 60:3675-3679. doi:10.1016/j.tet.2004.02.046.

25. Iglesias L, Aguilar C, Bandyopadhyay D, Banik BK (2010) A new Bismuth nitrate-catalysed electrophilic substitution of Indoles with carbonyl compounds under solevnt-free conditions. Synth Commun 40:3678-3682. doi:10.1080/00397910903531631.

26. Salvador JAR, Ppinto RMA, Silvestre SM (2009) Recent advances of bismuth (III) salts in organic chemistry: application to the synthesis of heterocycles of pharmaceutical interest. Curr Org Synth 6:426-470. doi:10.2174/ 157017909789108701.

27. Salvador JAR, Ppinto RMA, Silvestre SM (2009) Recent advances of bismuth (III) salts in organic chemistry: application to the synthesis of aliphatics, alicyclics, aromatics, amino acids and peptides, terpenes and steroids of pharmaceutical interest. Mini Rev Org Chem 6:241-274. doi:10.2174/ 157019309789371587.

28. Suzuki H, Matano Y (eds) (2001) Organobismuth chemistry. Elsevier, Amsterdam

29. Das S, Bora R, Devi RR, Thakur AJ (2008) Molecular iodine in protection and deprotection chemistry. Synletters 18:2741-2762

30. Saikia L, Das S, Thakur AJ (2011) Deprotection chemistry mediated by $\mathrm{ZrOCl}_{2} .8 \mathrm{H}_{2} \mathrm{O}$ : an efficient, mild and green method for the conversion of oximes to carbonyl compounds in aqueous acetone. Synth Commun 41:1071-1076. doi:10.1080/00397911003797783. 
31. Damljanovic I, Vukicevic M, Vukicevic RD (2006) A simple synthesis of oximes. Monatsh Chem 137:301-305. doi:10.1007/s00706-005-0427-3.

32. Irwing-Sax N, Bewis RJ (1989) Dangerous properties of industrial materials, Van Nostrand Reinhold, New York, pp 283-284, 522-523

33. Reglinski J, Norman NC, (eds) (1998) Chemistry of arsenic, antimony and bismuth. Blackie Academic and Professional, New York, pp 403-440

doi:10.1186/2191-2858-1-12

Cite this article as: Saikia et al:: A rapid, convenient, solventless green approach for the synthesis of oximes using grindstone chemistry. Organic and Medicinal Chemistry Letters 2011 1:12.

\section{Submit your manuscript to a SpringerOpen ${ }^{\circ}$ journal and benefit from:}

- Convenient online submission

- Rigorous peer review

- Immediate publication on acceptance

- Open access: articles freely available online

- High visibility within the field

- Retaining the copyright to your article

Submit your next manuscript at $\gg$ springeropen.com 